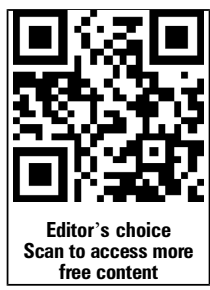

Department of Research, Insurance Institute for Highway Safety, Arlington, Virginia, USA

\section{Correspondence to}

Dr Anne T McCartt,

Department of Research, Insurance Institute for Highway Safety, 1005 N. Glebe Road, Suite 800, Arlington, Virginia 22201, USA amccartt@iihs.org

Received 13 August 2014 Revised 31 October 2014 Accepted 13 November 2014 Published Online First 18 December 2014

\title{
Type, size and age of vehicles driven by teenage drivers killed in crashes during 2008-2012
}

\author{
Anne T McCartt, Eric R Teoh
}

\section{ABSTRACT}

Given teenagers' elevated crash rates, it is especially important that their vehicles have key safety features and good crash protection. A profile of vehicles driven by teenagers killed in crashes was developed. Data on vehicles of drivers ages $15-17$ and ages 35-50 who died in crashes during 2008-2012 were obtained from the Fatality Analysis Reporting System. Using vehicle identification numbers, the vehicle make, model and model year were identified. $29 \%$ of fatally injured teenagers were driving mini or small cars, $82 \%$ were driving vehicles at least 6 years old, and $48 \%$ were driving vehicles at least 11 years old. Compared with middle-aged drivers, teenagers' vehicles more often were small or mini cars or older vehicles. Few teenagers' vehicles had electronic stability control or side airbags as standard features. Parents should consider safety when choosing vehicles for their teenagers.

\section{BACKGROUND}

Graduated driver licensing laws have been highly effective in reducing crash rates for younger teenagers. ${ }^{1-3}$ Beginning with Florida in 1996, all US states and the District of Columbia have implemented some form of graduated driver licensing. Consistent with the increasing presence of these laws, the risk of involvement in a police-reported or fatal crash for teenage drivers has declined substantially at the national level since 1996, whether based on per capita or mileage-based rates. ${ }^{4}$ Yet, per mile driven, rates of police-reported crashes and fatal crashes for teenagers are about three times the rates for adult drivers. ${ }^{5}$ Thus, researchers and others continue to seek ways to keep teenage drivers safer.

Parents are the primary enforcers of graduated licensing laws and are responsible for other important decisions related to their teenage drivers' safety. A critical parental responsibility is choosing the vehicle their teenager will drive. Using a safe vehicle is important for all drivers but especially so for teenagers given their elevated crash risk.

Several factors contribute to the relative safety of a given vehicle. All other things being equal, occupants in bigger, heavier vehicles are better protected than those in smaller, lighter vehicles. Both size and weight affect the forces experienced by vehicle occupants during crashes, and the magnitude of these forces is directly related to the risk of injury. Driver death rates per million registered 2005-2008 model passenger vehicles during 20062009 generally were lower in larger, heavier vehicles. ${ }^{6}$ For example, the rate of driver deaths per million registered vehicles was about 70 for cars weighing 3000 pounds or less, compared with about 40 for cars weighing 4001-4500 pounds.

Even among vehicles of comparable size and weight, some models have better structural designs and restraint systems that make them more crashworthy, as reflected in better crash test ratings from the Insurance Institute for Highway Safety and federal government. Vehicles earning good ratings in the moderate overlap front ${ }^{7}$ and side $^{8}$ crash tests are associated with lower driver death rates in frontal crashes and near-side crashes, respectively, than vehicles rated poor. Over time, the percentages of registered vehicles rated good or acceptable in crash tests have increased. ${ }^{9}$ Vehicle technologies that can prevent or mitigate crashes have become increasingly common. Electronic stability control (ESC) reduces fatal single-vehicle crash risk by about a half and fatal multiple-vehicle crash risk by $20 \%$ for cars and sport utility vehicles (SUVs). ${ }^{10}$ ESC can prevent loss-of-control crashes, which are prevalent among newly licensed teenage drivers. ${ }^{11}$ Newer model vehicles generally are safer than older models because vehicle crashworthiness has improved over time, and because they are more likely to be equipped with safety technologies such as side airbags and ESC.

Prior research found that teenagers often drive older or smaller vehicles. ${ }^{12} 13$ When parents in three states were interviewed in spring 2006 while their teenagers took the on-road driving test for licensure, the majority understood some of the important criteria for choosing safe vehicles for their teenagers but often selected vehicles that provided inferior crash protection. $^{12}$ In a national survey of parents of teenage drivers conducted in May 2014, parents ranked safety as the most important reason for choosing a particular vehicle for their teenagers, but many teenagers were not driving vehicles with the most important safety features or an acceptable level of crash protection. ${ }^{14}$ Specifically, about a fifth were driving mini or small cars, and 60\% were driving model year 2006 or older vehicles. In an analysis of automobile insurance data for 2000-2013 model year passenger vehicles during calendar years 20082012, teenagers ages 15-17 were more likely than $35-50$-year-olds to be the rated driver of small passenger cars, compared with other types/sizes of passenger vehicles, and the collision claim rates for teenagers rated to small cars were among the highest, with claim rates generally decreasing as vehicle size increases. ${ }^{15}$

The majority of collisions reported to insurers involve only property damage or relatively minor injuries. The following analyses profile the types, sizes and ages of vehicles driven by teenagers who died in highway crashes during 2008-2012. 
Table 1 Distribution (percent) of type and size of vehicles driven by fatally injured passenger vehicle drivers ages 15-17 and 35-50, 20082012

\begin{tabular}{|c|c|c|c|}
\hline & $\begin{array}{l}\text { Drivers ages } 15-17 \\
\mathrm{~N}=2420\end{array}$ & $\begin{array}{l}\text { Drivers ages } 35-50 \\
\mathrm{~N}=18975\end{array}$ & $\begin{array}{l}\text { Difference in estimated teenage } \\
\text { and middle-aged driver percentages }(95 \% \mathrm{CI})\end{array}$ \\
\hline \multicolumn{4}{|l|}{ Car } \\
\hline Mini/small & 28.5 & 19.5 & $9.0(7.1 \text { to } 10.9)^{*}$ \\
\hline Midsize & 23.4 & 16.3 & $7.1(5.4 \text { to } 8.9)^{*}$ \\
\hline Large/very large & 11.7 & 10.6 & $1.0(-0.3$ to 2.4$)$ \\
\hline Unknown size & 0.1 & 0.2 & \\
\hline \multicolumn{4}{|l|}{ Minivan } \\
\hline Large/very large & 1.8 & 4.3 & $-2.4(-3.0 \text { to }-1.8)^{*}$ \\
\hline \multicolumn{4}{|l|}{ Pickup } \\
\hline Small & 6.6 & 8.2 & $-1.6(-2.6 \text { to }-0.5)^{*}$ \\
\hline Large/very large & 10.3 & 16.5 & $-6.2(-7.5 \text { to }-4.9)^{*}$ \\
\hline Unknown size & 0.1 & 0.2 & \\
\hline \multicolumn{4}{|l|}{ SUV } \\
\hline Mini/small & 4.6 & 5.2 & $-0.6(-1.5$ to 0.3$)$ \\
\hline Midsize & 9.2 & 10.8 & $-1.7(-2.9 \text { to }-0.4)^{*}$ \\
\hline Large/very large & 2.9 & 4.7 & $-1.8(-2.6 \text { to }-1.1)^{*}$ \\
\hline Unknown/missing & 0 & $<0.1$ & \\
\hline Unknown vehicle type & 0.9 & 3.5 & \\
\hline Total & 100 & 100 & \\
\hline
\end{tabular}

\section{METHODS}

The types, sizes and ages of passenger vehicles driven by fatally injured teenage drivers ages $15-17(\mathrm{~N}=2420)$ were examined. As a comparison, the characteristics of passenger vehicles driven by fatally injured middle-aged drivers ages 35-50 ( $\mathrm{N}=18975)$ also were examined. Drivers ages 35-50 represent the approximate age range of most parents of teenagers ages $15-17$.

Data on vehicles driven by young teenagers and middle-aged drivers who died in crashes during 2008-2012 were obtained from the Fatality Analysis Reporting System, a census of motor vehicle crashes occurring on US public roads and resulting in at least one death within 30 days of the crash. Vehicle identification numbers were used to identify the make, model and model year of vehicles, which then were classified into type (car, minivan, SUV, pickup) and size (mini, small, midsize, large, very large) categories, using a categorisation system developed by the Highway Loss Data Institute and Insurance Institute for Highway Safety where a vehicle's size category depends on type. Subtracting model year from the year of the crash gives a measure of vehicle age, which was classified as newer than 3 years, 3-5 years, 6-10 years, 11-15 years, or 16 years or older.

CIs for the difference in estimated proportions were computed by using a normal distribution approximation given by the following:

$$
\left(\mathrm{p}_{1}-\mathrm{p}_{2}\right) \pm \mathrm{z}_{1-\alpha / 2} \operatorname{sqrt}\left[\mathrm{p}_{1}\left(1-\mathrm{p}_{1}\right) / \mathrm{n}_{1}+\mathrm{p}_{2}\left(1-\mathrm{p}_{2}\right) / \mathrm{n}_{2}\right]
$$

where $\mathrm{p}_{1}$ and $\mathrm{p}_{2}$ are the estimated proportions, $\mathrm{n}_{1}$ and $\mathrm{n}_{2}$ are the sample sizes, and $z_{1-\alpha / 2}$ is the $100(1-\alpha / 2)$ th percentile of the standard normal distribution. Proportions were expressed as percentages by multiplying by 100 . In the present study, $95 \%$ $(\alpha=0.05)$ CIs were provided, so $z_{1-0.05 / 2}=1.96$ was used to judge statistical significance.

\section{RESULTS}

As shown in table 1, about two-thirds of the teenage drivers who died in crashes were driving a car, with $29 \%$ driving a mini or small car and $35 \%$ driving a midsize or larger car. About $17 \%$ were driving pickups, primarily large or very large pickups $(10 \%)$, and about $17 \%$ were driving SUVs-mini or small $(5 \%)$, midsize $(9 \%)$, or large or very large $(3 \%)$. In all, $2 \%$ were driving minivans.

Fatally injured teenage drivers were significantly more likely than fatally injured middle-aged drivers to have been driving a mini or small car $(28 \%$ vs $20 \%)$ or a midsize car $(23 \%$ vs $16 \%)$ and significantly less likely to have been driving a large or very large pickup (10\% vs $16 \%)$.

Overall, $82 \%$ of the vehicles driven by fatally injured teenage drivers were 6 years old or older (table 2), including 34\% that were $6-10$ years old, $31 \%$ that were $11-15$ years old and $17 \%$ that were 16 years old or older. The age of vehicles driven by teenagers was skewed somewhat older than the age of vehicles driven by middle-aged drivers. For example, $23 \%$ of the vehicles

Table 2 Distribution (percent) of age of vehicles driven by fatally injured passenger vehicle drivers ages $15-17$ and 35-50, 2008-2012

\begin{tabular}{llll}
\hline Vehicle age & $\begin{array}{l}\text { Drivers } \\
\text { ages } \\
\mathbf{1 5 - 1 7}\end{array}$ & $\begin{array}{l}\text { Drivers } \\
\text { ages 35- } \\
\mathbf{5 0}\end{array}$ & $\begin{array}{l}\text { Difference in estimated } \\
\text { teenage and middle-aged } \\
\text { driver percentages }(95 \% \mathrm{Cl})\end{array}$ \\
\hline & $\mathrm{N}=2420$ & $\mathrm{~N}=18975$ & \\
$<3$ years & 6.1 & 8.4 & $-2.2(-3.3 \text { to }-1.2)^{*}$ \\
3-5 years & 12.0 & 14.2 & $-2.2(-3.5 \text { to }-0.8)^{*}$ \\
6-10 years & 34.2 & 31.2 & $3.0(1.0 \text { to } 5.0)^{*}$ \\
11-15 years & 30.8 & 26.4 & $4.4(2.4 \text { to } 6.3)^{*}$ \\
16+ years & 16.9 & 19.8 & $-2.9(-4.5 \text { to }-1.3)^{*}$ \\
Unknown & 0 & 0.1 & \\
\hline
\end{tabular}

${ }^{*}$ Difference statistically significant at $\alpha=0.05$. 
Table 3 Distribution (percent) of type and age of vehicles driven by fatally injured passenger vehicle drivers ages 15-17 and 35-50, 2008-2012

\begin{tabular}{|c|c|c|c|}
\hline Vehicle age & $\begin{array}{l}\text { Drivers } \\
\text { ages } \\
15-17 \\
\mathrm{~N}=2420\end{array}$ & $\begin{array}{l}\text { Drivers } \\
\text { ages } \\
35-50 \\
\mathrm{~N}=18975\end{array}$ & $\begin{array}{l}\text { Difference in estimated } \\
\text { teenage and middle-aged } \\
\text { driver percentages } \\
(95 \% \mathrm{Cl})\end{array}$ \\
\hline \multicolumn{4}{|l|}{ Car } \\
\hline$<3$ years & 4.8 & 4.7 & $0.1(-0.8$ to 1.0$)$ \\
\hline $3-5$ years & 7.7 & 6.7 & $1.0(-0.1$ to 2.1$)$ \\
\hline $6-10$ years & 21.1 & 13.2 & $7.8(6.2 \text { to } 9.5)^{*}$ \\
\hline $11-15$ years & 20.0 & 12.4 & $7.7(6.0 \text { to } 9.3)^{*}$ \\
\hline $16+$ years & 10.0 & 9.6 & $0.4(-0.9$ to 1.7$)$ \\
\hline \multicolumn{4}{|l|}{ Minivan } \\
\hline$<3$ years & $<0.1$ & 0.1 & $-0.1(-0.2 \text { to } 0.0)^{*}$ \\
\hline $3-5$ years & 0.1 & 0.6 & $-0.5(-0.7 \text { to }-0.3)^{*}$ \\
\hline $6-10$ years & 0.7 & 1.5 & $-0.8(-1.1 \text { to }-0 . .4)^{*}$ \\
\hline $11-15$ years & 0.6 & 1.4 & $-0.8(-1.2 \text { to }-0.5)^{*}$ \\
\hline $16+$ years & 0.3 & 0.6 & $-0.3(-0.5 \text { to }-0.0)^{*}$ \\
\hline \multicolumn{4}{|l|}{ Pickup } \\
\hline$<3$ years & 0.7 & 1.9 & $-1.1(-1.5 \text { to }-0.7)^{*}$ \\
\hline $3-5$ years & 2.0 & 3.6 & $-1.6(-2.3 \text { to }-1.0)^{*}$ \\
\hline $6-10$ years & 5.3 & 7.5 & $-2.2(-3.1 \text { to }-1.2)^{*}$ \\
\hline $11-15$ years & 4.3 & 6.0 & $-1.6(-2.5 \text { to }-0.7)^{*}$ \\
\hline $16+$ years & 4.5 & 5.8 & $-1.3(-2.2 \text { to }-0.4)^{*}$ \\
\hline \multicolumn{4}{|l|}{ SUV } \\
\hline$<3$ years & 0.5 & 1.3 & $-0.9(-1.2 \text { to }-0.6)^{*}$ \\
\hline $3-5$ years & 2.1 & 2.7 & $-0.6(-1.2$ to 0.0$)$ \\
\hline $6-10$ years & 6.9 & 8.2 & $-1.4(-2.5 \text { to }-0.3)^{*}$ \\
\hline $11-15$ years & 5.5 & 6.1 & $-0.6(-1.6$ to 0.4$)$ \\
\hline $16+$ years & 1.7 & 2.4 & $-0.6(-1.2 \text { to }-0.1)^{*}$ \\
\hline $\begin{array}{l}\text { Unknown vehicle } \\
\text { type }\end{array}$ & 0.9 & 3.5 & \\
\hline Total & 100 & 100 & \\
\hline
\end{tabular}

of fatally injured middle-aged drivers were 3 years old or newer $(8 \%)$ or $3-5$ years old (14\%), compared with $6 \%$ and $12 \%$, respectively, for teenage drivers; these differences were statistically significant.

About half of the vehicles driven by fatally injured teenagers were cars 6 years old or older, compared with about a third of the vehicles of fatally injured middle-aged drivers (table 3). Compared with the vehicles of fatally injured middle-aged drivers, the vehicles of fatally injured teenage drivers were significantly more likely to be $6-10$ years old $(21 \%$ vs $13 \%)$ or $11-15$ years old (20\% vs $12 \%)$.

Among cars that were 2 years old or newer and driven by teenagers, mini or small cars accounted for 57\% (table not shown).

Reflecting the older model years of many of the vehicles driven by teenage drivers, no more than about $12 \%$ of teenagers' vehicles had ESC as a standard $(3 \%)$ or optional $(8 \%)$ feature (table not shown). About $15 \%$ of adults' vehicles had ESC as a standard (7\%) or optional (9\%) feature. The difference in the availability of ESC on teenage and adult vehicles was significant $(-3.2 \%$ difference, $95 \% \mathrm{CI}-4.6$ to -1.8$)$. In all, $36 \%$ of the vehicles of both teenagers and adults had optional or standard side airbags, but adults' vehicles were slightly more likely to have side airbags as a standard feature (14\% vs $12 \%$; $-1.9 \%$ difference, $95 \%$ CI -3.3 to -0.6$)$. Among the vehicles with these features as options, it is expected that the large majority were not actually equipped with the features as the purchase of optional safety features in the USA historically has been low.

\section{DISCUSSION}

Given the elevated crash rates of teenage drivers relative to adult drivers, it is especially important that teenagers drive vehicles that have key safety features and provide good protection in the event of a crash. Larger, heavier vehicles generally provide much better crash protection than smaller, lighter ones. Newer vehicles generally are also more likely to have better crash test ratings and important safety features such as ESC and side airbags. Yet, many teenage drivers who died in highway crashes during 2008-2012 were driving mini or small cars, and many were driving older vehicles. Few teenagers' vehicles had ESC or side airbags as standard features, despite the proven effectiveness of these technologies. Even when teenagers were driving newer cars (2 years old or newer), more than half of these vehicles were mini or small cars.

Due to a lack of detailed data on driving exposure by vehicle type and size, it is not known to what extent these findings reflect the kinds of vehicles teenagers are driving and to what extent they reflect the relative safety of the vehicles they drive. While much is known about the relative safety of vehicles based on size and weight, crash test ratings, and safety features, recent research suggests there may be an exposure effect as well. A recent analysis of automobile insurance data found that 1517-year-olds were more likely than 35-50-year-olds to be the rated driver of small passenger cars, and the collision claim rates for teenagers rated to small cars were 2.6 times as high as for prime-age drivers. ${ }^{15}$ In a national telephone survey conducted in May 2014, about a fifth of parents said that their teenagers were driving mini or small cars, compared with $28 \%$ of the fatally injured teenage drivers in the current study. ${ }^{14}$ Parents reported that $60 \%$ of teenagers were driving model year 2006 or older vehicles; in the current study, $82 \%$ of fatally injured teenagers were driving vehicles at least 6 years old. Parents may benefit from consumer information about vehicle choices that are both safe and economical. ${ }^{16}$

\section{What is already known on the subject}

As teenagers have elevated crash rates relative to adults, it is especially important that teenagers drive safe vehicles.

- Larger, heavier vehicles generally provide better crash protection, and newer vehicles are more likely to have better crash test ratings and important safety features.

\section{What this study adds}

- Teenage drivers killed in crashes generally are not driving safer types of vehicles in terms of size and availability of safety features.

- The superior safety profile of vehicles driven by fatally injured middle-aged drivers suggests room for improvement in the vehicles driven by teenagers. 
Contributors Both authors contributed to the design of the study, analysis of data, interpretation of results and writing the manuscript.

Funding This work was supported by the Insurance Institute for Highway Safety.

Competing interests None.

Provenance and peer review Not commissioned; externally peer reviewed.

\section{REFERENCES}

1 McCartt AT, Teoh ER, Fields M, et al. Graduated licensing laws and fatal crashes of teenage drivers: a national study. Traffic Inj Prev 2010;11:240-48.

2 Shope JT, Molnar LJ. Graduated driver licensing in the United States: evaluation results since 2002. J Safety Res 2007;38:166-75.

3 Trempel RE. Graduated driver licensing laws and insurance collision claim frequencies of teenage drivers. Arlington, VA: Highway Loss Data Institute, 2009.

4 McCartt AT, Teoh ER. Tracking progress in teenage crash risk in the United States since the advent of graduated driver licensing programs. Arlington, VA: Insurance Institute for Highway Safety, 2014.

5 Insurance Institute for Highway Safety. Unpublished analysis of 2008 data from the U.S. Department of Transportation's National Household Travel Survey, General Estimates System, and Fatality Analysis Reporting System. Arlington, VA: IIHS, 2014

6 Insurance Institute for Highway Safety. Dying in a crash. Status Report 2011:46:1-7. Arlington, VA: IHS.
7 Farmer CM. Relationships of frontal offset crash test results to real-world driver fatality rates. Traffic Inj Prev 2005;6:31-7.

8 Teoh ER, Lund AK. IIHS side crash test ratings and occupant death risk in real-world crashes. Traffic Inj Prev 2011;12:500-7.

9 Highway Loss Data Institute. IIHS crashworthiness evaluation programs and the U.S. vehicle fleet. Bulletin Arlington, VA: HLDI. 2013;30:1-10.

10 Farmer CM. Effects of electronic stability control on fatal crash risk. Arlington, VA: Insurance Institute for Highway Safety, 2010.

11 Braitman KA, Kirley BB, McCartt AT, et al. Crashes of novice teenage drivers: characteristics and contributing factors. J Safety Res 2008;39:47-54.

12 Hellinga LA, McCartt AT, Haire ER. Choice of teenagers' vehicles and views on vehicle safety: survey of parents of novice teenage drivers. I Safety Res 2007;38:707-13.

13 Williams AF, Leaf WA, Simons-Morton BG, et al. Vehicles driven by teenagers in their first year of licensure. Traffic Inj Prev 2006;7:23-30.

14 Eichelberger AH, Teoh ER, McCartt AT. Vehicle choices for teenage drivers: a national survey of parents. Arlington, VA: Insurance Institute for Highway Safety, 2014.

15 Highway Loss Data Institute. Young teen crash risk by vehicle type. Bulletin Arlington, VA: HLDI. 2014;31:1-6.

16 Insurance Institute for Highway Safety. Choosing the best vehicle for your teen. Arlington, VA: IIHS, 2014. http://www.iihs.org/iihs/ratings/vehicles-for-teens (accessed 28 Oct 2014).

\section{Two-year-old shoots mother}

A 2-year-old boy unintentionally shot and killed his mother after he reached into her purse and found a small calibre handgun. The mother had a concealed gun weapons permit. Comment: The shooting is described as 'incidental' but not everyone agrees. I am curious to see what the NRA have to say about giving concealed weapons permits to mothers of 2-year-olds.

\section{Baby shot by 5-year-old brother}

A 9-month-old boy was shot and killed by his 5 -year-old brother after the boy found his grandfather's revolver. At the time of the shooting, another child was playing with a paintball gun and there were several other weapons in the home. The sheriff viewed the incident as a tragic, if cautionary, tale. He said, ".....we pretty much assume that in about every home that we go into, there are firearms there" adding, "... and that's okay because it's legal".

\section{Parents encourage toddler to put handgun in mouth}

A couple was charged with child neglect when a video was found that shows their 1-year-old baby playing with a gun and the pair telling her to put it in her mouth. The couple were also charged with criminal recklessness with a deadly weapon. Police stated, "Gun ownership is a right in America, but it's also a responsibility". 